\title{
Optimisation of the machining of Stellite 6 PTA hardfacing using surface roughness
}

\author{
Md Shahanur Hasan ${ }^{1, a}$, Abdul Md Mazid ${ }^{2, b}$ and Richard E.Clegg ${ }^{3, c}$ \\ The Centre for Process Engineering \& Light Metals (PELM) \\ Faculty of Sciences, Engineering \& Health \\ CQUniversity Australia, Rockhampton, Australia

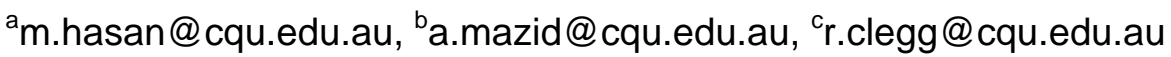

Keywords: Stellites, difficult-to-machine materials, machining regime optimization, surface roughness

\begin{abstract}
Stellites are cobalt based super alloys. By virtue of their excellent physio-mechanical properties, stellites are highly regarded engineering materials. Stellites posses high corrosion resistance and wear resistance properties.. This study investigates the Stellite deposition process and machinability of Stellite 6 deposited on steel subtrate. Stellite 6 was deposited onto a 4140 bar using a plasma transfer arc (PTA) system and machinability was assessed on the basis of surface roughness. A series of turning operations have been carried out on a conventional lathe using coated carbide inserts and surface roughness was evaluated by Stylus type Surtronic3+ instrument. The values of surface roughness were plotted against different cutting speed, feed rate and depth of cut to display the results in graphical forms. Optimal cutting regimes were established against the best values of surface roughness.
\end{abstract}

\section{Background}

Stellites are cobalt based super alloys, Elwood P. Haynes developed this alloys for incorporating corrosion resistant automobile parts (spark plugs) and in 1900s he named Stellite following the latin word Stella meaning star as the metallographic structure of it looks alike.By virtue of their excellent physio-mechanical properties Stellites are highly regarded engineering alloys. These Cobalt based alloys posses superior corrosion and oxidation resistances, excellent sliding wear and abrasion wear resistance properties as well, good magnetic properties and cracking resistance property.Parts made of Stellites are capable to work and maintain these superior properties at higher temperature and in aggressive environment $[1,7]$. Stellites are found in two combinations: Tungsten (W) - containing (Co-Cr-W-C) such as Stellites 6, 12, 1, and 190, and Molebdenum (Mo) - containing (Co-Cr-MoC), examples, Stellites 706, 712, 701, and 790. Presence of higher percentage Chromium (Cr) provides Stellite alloys with good magnetic and corrosion resistance properties [2, 3]. Chromium acts as carbide former which offers corrosion resistance, and it plays the role of the most important strengthening element in the alloy matrix [5]. This paper deals with machining of Stellite 6 and mechanical properties of Stellite 6 are displayed below in Table 1.

Table 1. Mechanical properties of stellite 6

\begin{tabular}{|l|l|l|l|l|l|l|}
\hline Alloy & $\begin{array}{l}\text { Density, } \\
\rho\left(\mathrm{g} / \mathrm{cm}^{3}\right)\end{array}$ & $\begin{array}{l}\text { Yield } \\
\text { Strength, } \mathrm{S}_{\mathrm{y}} \\
{[\mathrm{MPa}]}\end{array}$ & $\begin{array}{l}\text { Ultimate Tensile } \\
\text { Strength, } \\
\mathrm{S}_{\mathrm{ut}}[\mathrm{MPa}]\end{array}$ & $\begin{array}{l}\text { Hardness } \\
{[\mathrm{HRC}]}\end{array}$ & $\begin{array}{l}\text { Elongation } \\
{[\%]}\end{array}$ & $\begin{array}{l}\text { Melting } \\
\text { Range, } \\
\mathrm{T}\left[{ }^{0} \mathrm{C}\right]\end{array}$ \\
\hline Stellite 6 & 8.9 & 541 & 896 & 40 & 1 & $1285-1395$ \\
\hline
\end{tabular}

Stellites have a number of advantages over other materials. The first is that they show excellent metal on metal anti galling behaviour and are often used in situations where metal-on-metal sliding occurs. Stellites also show good wear resistance in high corrosive media and have a very high 
corrosion resistance. Stellites can also be deposited through deposition techniques such as PTA (plasma transfer arc) and so have been used extensively as hardfacing materials in industries such as alumina production.

Stellites are used to hardface certain slurry valves for use in alumina refineries where the wear rates are very high. These valves need to be machined precisely in order to prevent leakage and excessive wear in the valves. The rationale behind using stellite is to provide a corrosion resistant and wear resistant surface which will help combat the wear of the valves. However, wear resistant materials are naturally difficult to machine. In this paper, we examine the machinability of Stellite 6 from the point of view of surface roughness in order to enable the optimisation of machining of this component and enable Stellite 6 surfaces to be machined in an economic manner for use in the minerals industry.

\section{Materials and Methods}

\section{Deposition of the Stellite 6}

Stellite 6 was deposited onto $100 \mathrm{~mm}$ diameter bars of AISI 4140. The steel bar was preheated to $260^{\circ} \mathrm{C}$ using a oxyacetylene torch and allowed to soak to an average preheat temperature of $150^{\circ} \mathrm{C}$ prior to deposition. The stellite powder was deposited at a rate of $11.5 \mathrm{gm} / \mathrm{min}$ in a PTA system at $120 \mathrm{~A}$ and $26.2 \mathrm{~V}$. The bar was rotated at $1.5 \mathrm{rpm}$ and the PTA bead was moved along the bar at a pitch of approximately $8 \mathrm{~mm}$ to provide a continuous layer of Stellite 6 on the bar approximtely 250 $\mathrm{mm}$ long. Four bars of Stellite 6 were produced in this manner, with three bars having a single layer of Stellite and one bar having two layers of Stellite. One of the problems with a single layer of stellite is that dilution of the Stellite by the predominantly iron subtrate tends to alter the properties of the material, whereas the outer layer of the two-layer system will have significantly less dilution. The nominal chemical composition of the Stellite 6 powder prior to deposition was Cr-29\%, W-4.5\%, Mo-1.5\%, C-1.2\%, Fe-3\%, Ni-3\%, Si-1.5\%, Mn-1\%.

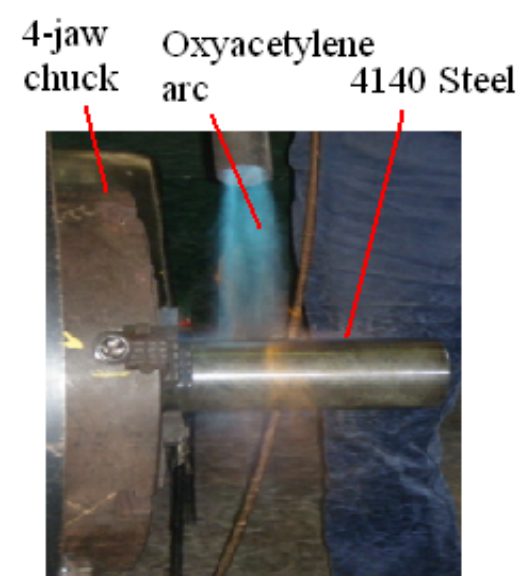

Fig.1 Steel bar heating process

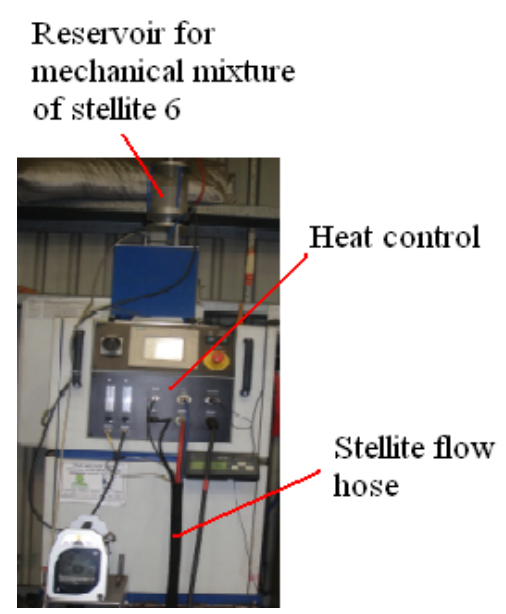

Fig.2 Plasma arc cladding unit 


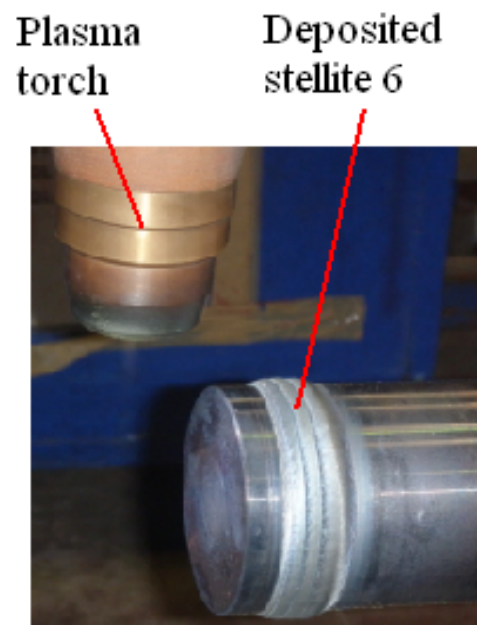

Fig.3 Stellite deposition process

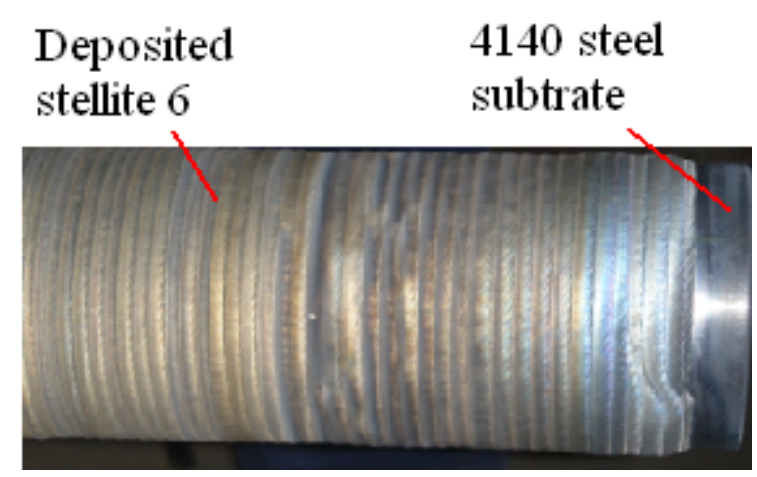

Fig.4 Deposited stellite bar for machining

\section{Machining Procedure}

A series of physical experiments have been performed for cutting parameter optimisation on a conventional Harrison M400 lathe . Coated carbide inserts were used. The tool geometry parameters were: lead angle $95^{\circ}$, rack angle $-6^{0}$ and nose radius $0.8 \mathrm{~mm}$.

In order to prepare the Stellite surface, the as-deposited surface was turned to a regular cylinder using coated carbide inserts.

\section{Cutting speed optimisation:}

Cutting speed was varied from $10 \mathrm{~m} / \mathrm{min}$ to $250 \mathrm{~m} / \mathrm{min}$ in eight steps. Machining fluid was applied at all stages. Eight steps of turning operations have been performed (Fig The depth of cut $(\mathrm{d}=0.5 \mathrm{~mm})$ and feed rate $(\mathrm{f}=0.1 \mathrm{~mm} / \mathrm{rev})$ remain constant for these experiments. During the experiment, crater wear was observed at a cutting speed of $200 \mathrm{~m} / \mathrm{min}$ and and the tool was replaced at this point. Significant tool wear also occurred at a cutting speed of $250 \mathrm{~m} / \mathrm{min}$ and sparking was observed in the cutting zone. Then, the tool damage started with ignition at cutting speed $315 \mathrm{~m} / \mathrm{min}$. The surface roughness $(\mathrm{Ra})$ for each of the samples were measured using a Taylor Hobson Surtronic 3+ instrument. Three measurements were taken along the shaft axis for each trial apart about $120^{\circ}$. The average values of surface roughness were calculated and plotted in Figure 7.

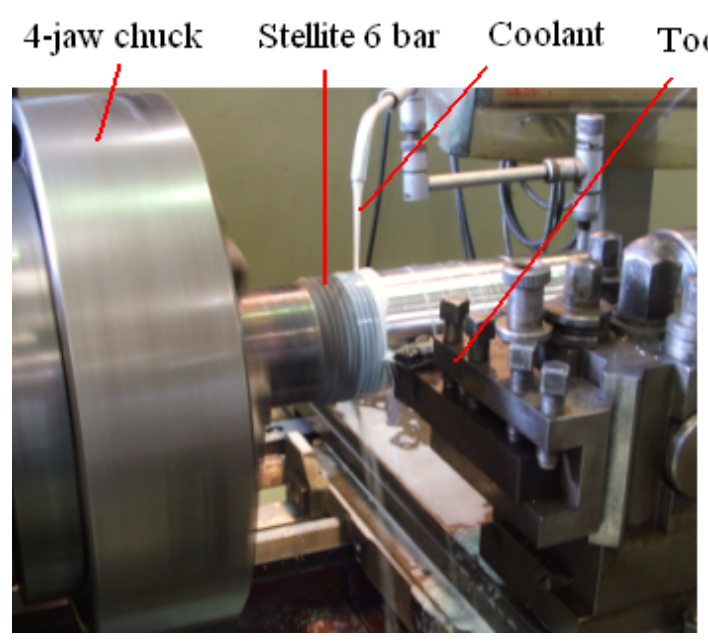

Fig.5 Lathe set up

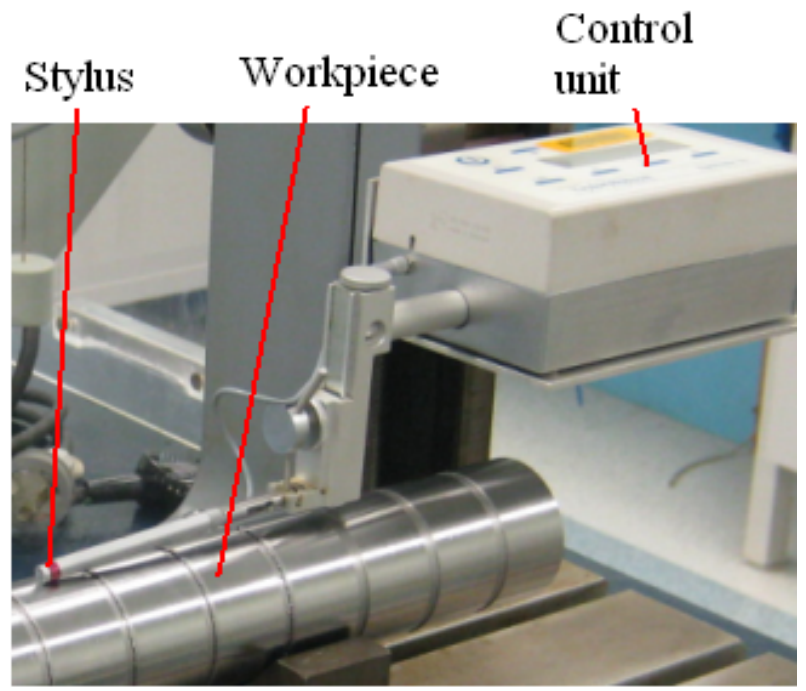

Fig.6 Surtronic 3+ 


\section{Feed rate optimisation:}

The feed rate was varied from $0.04 \mathrm{~mm} / \mathrm{rev}$ to $0.35 \mathrm{~mm} / \mathrm{rev}$ in seven stages at a cutting speed of 80 $\mathrm{m} / \mathrm{min}$ and a depth of cut of $0.5 \mathrm{~mm}$. Signifciant tool wear was observed at $0.28 \mathrm{~mm} / \mathrm{rev}$ feed rate after 5 minutes and a new tool was used for the remained of the experiment. The surface quality as measured using the Surtronic 3+ began to deteriorate as the feed rate increased, as shown in Figure 8 .

\section{Depth of cut optimisation:}

The depth of cut was varied from $0.08 \mathrm{~mm}$ to $1.4 \mathrm{~mm}$ in six stages and the surface roughness was measured in the same manner as described above Figure 9 shows the results of the experiments and as can be seen, the roughness increases as depth of cut is increased.

\section{Discussion}

As can be seen in Figure 7, surface roughness values are higher at lower cutting speeds and these values are decreasing with increasing cutting speed. However, the same graph suggests that surface roughness values are again in increasing trend with higher cutting speed. Therefore, lower cutting speed and higher cutting speed may not be recommended for machining of Stellite 6 components. The graph on Figure 7 suggests that, ranges of optimum cutting speed for turning Stellite 6 using coated carbide tools ranges between $50 \mathrm{~m} / \mathrm{min}$ to $80 \mathrm{~m} / \mathrm{min}$ while average surface roughness values are 0.93 to $0.86 \mu \mathrm{m}$ as shown in Fig.7. However, PTA deposited stellite is not a unform material with some variation expected along the length of the bar, which is likely to influence the cutting forces, chatter and vibration and hence the surface integrity [6].

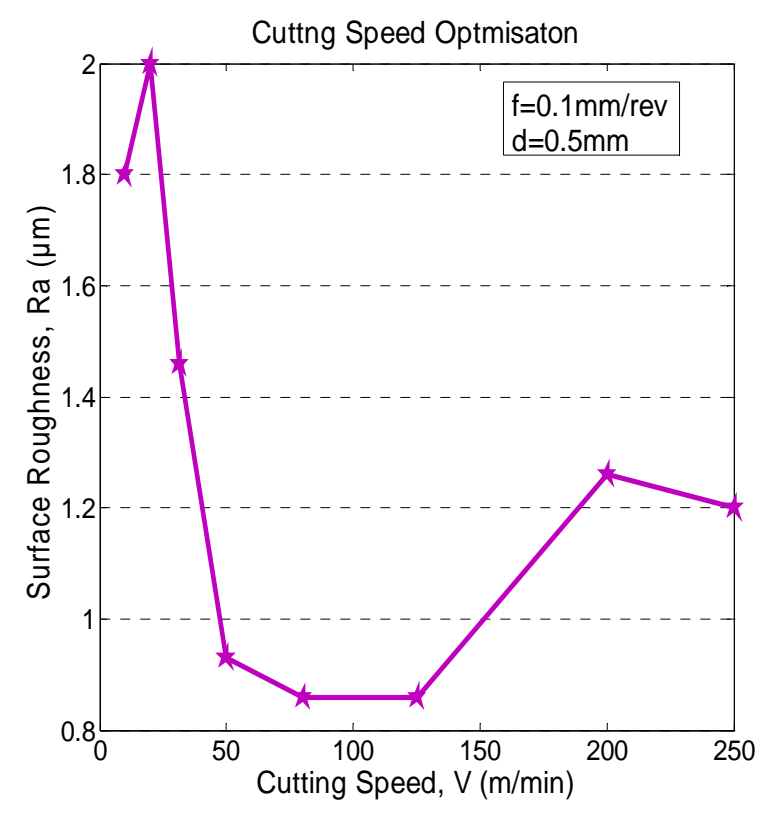

Fig.7 Optimisation graph for cutting speed

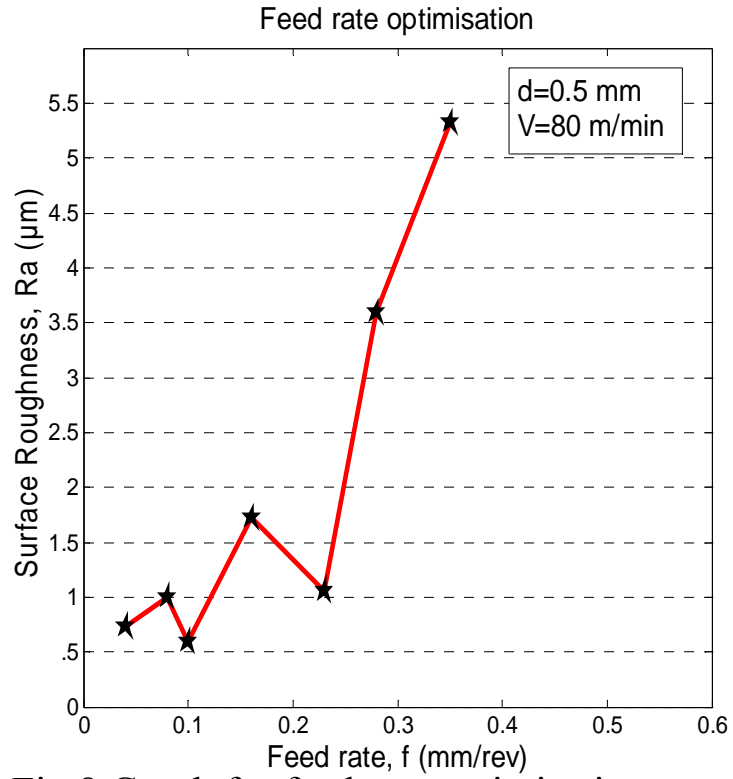

Fig.8 Graph for feed rate optimisation

Figure 8 shows that surface roughness increases with rising feed rates. It is also observed that surface roughness values were fluctuated, presumably because of non-uniform surface properties which are developed during stellite deposition and cooling of the sample. Therefore, optimum feed rate values are $0.04 \mathrm{~mm} / \mathrm{rev}$ to $0.1 \mathrm{~mm} / \mathrm{rev}$ while surface roughness values are 0.6 to $1 \mu \mathrm{m}$. It was found that the feed rate and cutting speed had the most influence on surface quality and this is in good agreement with previously published research work [8]. 


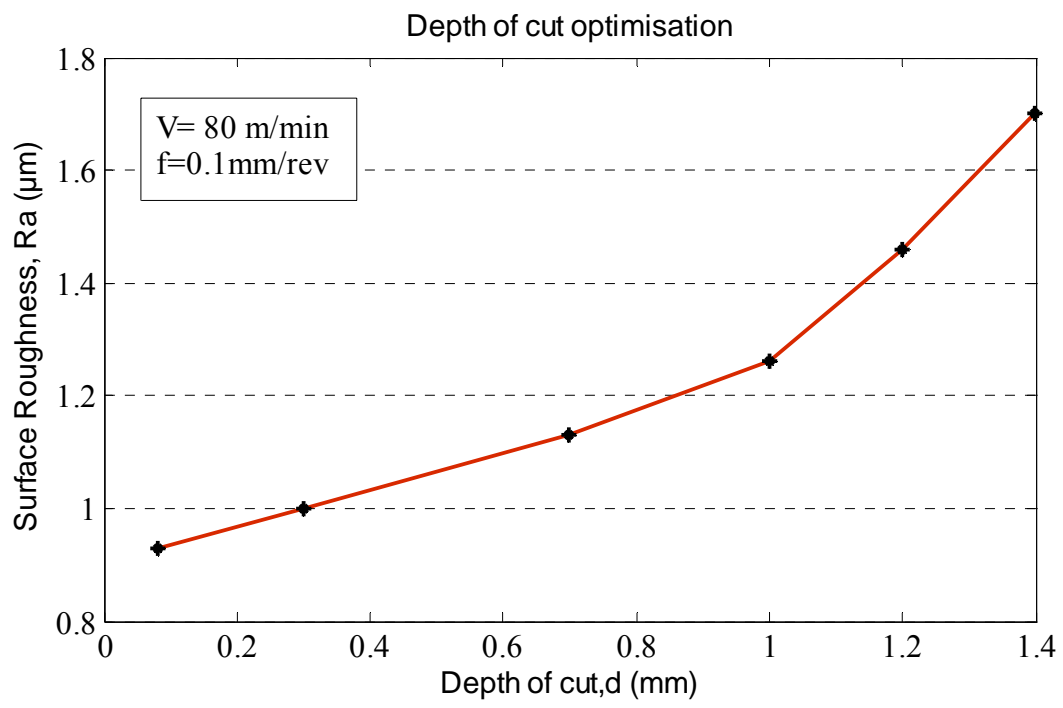

Fig.9 Optimisation graph for depth of cut

From the graph in Fig.9, it can be observed that values of surface roughness are gradually increasing with increasing of depth of cut. Therefore, lower values of depth of cut are recommended for better surface quality which ranges up to $0.8 \mathrm{~mm}$.

\section{Conclusions}

A first attempt of machining Stellite 6 has been made successfully A series of machining experiments on Stellite 6 bars with new grade of coated carbide insert has offered best optimum cutting regimes (cutting speed, feed rate and depth of cut) recorded in three separate graphs in this paper. For machining Stellite 6 using coated carbide inserts, it has been found that lower value of depth of cut and feed rate are better for best surface quality. Optimum cutting regimes are cutting speed (v) ranges from $50 \mathrm{~m} / \mathrm{min}$ to $80 \mathrm{~m} / \mathrm{min}$, feed rate (f) from $0.04 \mathrm{~mm} / \mathrm{rev}$ to $0.1 \mathrm{~mm} / \mathrm{rev}$ and depth (d) of cut from $0.08 \mathrm{~mm}$ to $0.8 \mathrm{~mm}$.

\section{Acknowledgement}

The authors acknowledge contribution of Gary Hoare at CQUniversity Australia and the Berg Engineering QLD Australia for their sincere helps in running experiments and the PELM Centre for adequate support in this research work.

\section{References}

[1] Website, www.stellite.com.

[2] Yao, M.X. ,Wu, J.B.C. , Xie, Y., Wear, corrosion and cracking resistance of some W- or Mo-containing Stellite hard-facing alloys, Material Science and Engineering A 407 (2005) 234-244.

[3] Bagci, Eyup, Aykut, Seref, A study of Taguchi optimization method for identifying optimum surface roughness in CNC face milling of cobalt-based alloy (stellite 6), Internation Journal of Advanced Manufacturing Technology (2006) 29: 940-947.

[4] Radu, Iulian, Li, D.Y., The wear performance of yttrium-modified Stellite 712 at elevated temperature, Tribology International 40 (2007) 254-265. 
[5] Ning, Y., Patnaik, P.C. , Liu, R. ,Yao, M.X. ,Wu, X.J. ,Effects of fabrication process and coating of reinforcements on the microstructure and wear performance of Stellite alloy composites, Material Science and Engineering A 391 (2005) 313-324.

[6] Mazid, M.A - Evaluation of dynamic qualities of lathe machines to categorise them for better productivity and accuracy avoiding defects. Proceedings, Fifth Australian Congress on Applied Mechanics 2007(ACAM 2007), Brisbane. Pp. 806-811.

[7] Rakesh Kaul, Ganesh, P, Tiwari, M.K, Singh, A.K, Tripathi,P, Gupta,A, Nath, A.K, Laser Assisted Deposition of Graded Overlay of Stellite 6 on Austenitic Stainless Steel, Lasers in Engineering, Volume 12, Issue 3 2002, pages $207-225$.

[8] Mazid A. M, Hasan M S, \& Clegg R - A Rational Between Manufacturing Processes Design And Manufacturing Cost; Advances in Materials and Processing Technologies Conference (AMPT 2009), Kuala Lumpur, October 2009, accepted paper presented in the conference. 